\title{
Implementing a provincial case mix adjusted funding model for inpatient rehabilitation activity: the impact on bed designations Jan Walker*1 and Jason Sutherland ${ }^{2}$
}

\author{
Address: ${ }^{1}$ Department of Public Health Sciences, University of Toronto, Canada and ${ }^{2}$ The Dartmouth Institute for Health Policy and Clinical \\ Practice, Dartmouth College, Hanover, NH, USA \\ Email: Jan Walker* - jan-walker@rogers.com \\ * Corresponding author
}

from 23rd Patient Classifications Systems International (PCSI) Working Conference

Venice, Italy. 7-10 November 2007

Published: 26 November 2007

BMC Health Services Research 2007, 7(Suppl I):A2 doi:I0.1 186/I472-6963-7-SI-A2

This abstract is available from: http://www.biomedcentral.com/I472-6963/7/SI/A2

(c) 2007 Walker and Sutherland; licensee BioMed Central Ltd.

\section{Background}

This paper will describe the implementation of a case mix system for inpatient rehabilitation activity in Ontario and review the impact of the implementation on hospital bed designation in the province.

\section{Data}

In the fall of 2002, the Ontario Ministry of Health and Long Term Care (MOHLTC) mandated the collection of National Rehabilitation Reporting System (NRS) data in all designated adult inpatient rehabilitation beds. From these data we developed a case mix grouping methodology with associated weights. Together these are being used to incorporate adult inpatient rehabilitation activity into the Integrated Population Based Allocation (IPBA) hospital funding formula. In Ontario, designated inpatient rehabilitation is typically provided in two sectors. Within the acute care sector, hospitals may or may not have designated rehabilitation beds. Even in hospitals that do not have designated rehabilitation beds, a patient may receive some rehabilitation while an inpatient, or on an outpatient basis. For example, a patient who has just had surgery may be visited by a physiotherapist to increase rangeof-motion and strength while recovering from surgery. Within the rehabilitation hospital sector, facilities typically have designated rehabilitation beds and are usually referred to as rehabilitation hospitals. The care in these facilities is often organized on a programmatic basis, time limited and goal oriented. For example, a facility may have a stroke rehabilitation program that is 6 to 8 weeks long for individuals following stroke. These programs are provided on an inpatient basis and may or may not have an outpatient component at the end. Rehabilitation is also provided in other sectors of the health care system, but not on a designated inpatient basis. Provincial Implementation:

\section{Results and discussion}

The province followed a three year implementation plan. During the first year data quality and completeness issued were identified. During the second year these issues were addressed, and regional education sessions were held to educate providers on the new case mix system. In response to the provincial implementation, certain facilities embarked on case mix reviews. These reviews included grouping their inpatient rehabilitation data for the first time in order to understand their case mix distribution and to investigate the issue of 'specialty populations'. One specific issue uncovered was the appropriateness of care being provided in designated rehabilitation beds. For example, Tuberculosis care was being provided in designated rehabilitation beds, however, the care was not typical rehabilitative care. We will discuss the implications of issues such as this and the potential for re-organization of bed designations in this sector. 